\title{
AKTIVITAS ANTIOKSIDAN SENYAWA FLAVONOID DARI KULIT BATANG LEGUNG (Vitex pinnate Tour ex Linn) DENGAN METODA TIOSIANAT
}

\author{
Musyirna Rahmah Nasution"), Dasni Syafril'), Yuharmen ${ }^{3)}$ \\ ${ }^{1)}$ Sekolah Tinggi Ilmu Farmasi Riau, ${ }^{2,3)}$ Universitas Riau
}

\begin{abstract}
ABSTRAK
Antioxidant are the compounds capable to inhibit free radical reactions in the human body.This research was aimed to identify the antioxidant potency of flavonoid compound of extract metanol of legung bark (Vitex pinnate Tour ex Linn) by using linoleic-tyocyanate methods.The result suggested, that isolated flavonoid of methanol extract was produced five fraction and most of fraction conducted antioxidant activity more less than $\alpha$-tokoferol. But, Two Fraction which is recristalization was the higer than a-tokoferol and vitamin $C$
\end{abstract}

Key word: flavonoid, antioxidant, linoleic-tyocyanate methods

\section{PENDAHULUAN}

Di Indonesia tumbuhan famili Verbenaceae tumbuh di daerah pantai atau berpasir pada ketinggian 1-800 diatas permukaan laut. Tumbuhan ini termasuk tumbuhan liar dan menyukai tempat-tempat terbuka seperti pinggir jalan, tanah kosong bekas garapan dan juga dikatakan tumbuhan semak (Sugiarto, 1996). Berdasarkan kandungannya tumbuhan Verbenaceae banyak mengandung flavonoid dan diterpenoid. Tahun 1995, Alphaljit menemukan senyawa diterpenoid dengan kerangka dasar Labdane seperti limunidilakton dari spesies Vitex limonifloia dan Subramaniem dan Misra berhasil mengisolasi senyawa 6-C-Glikosil-5,7dihidroksil-8,3', 4',5' tetrahidroflavonoid dari spesies Vitex negundo. Sebahagian besar tanaman dari famili ini penhasil obatobatan antara lain Vitex trifolia Linn sebagai obat setelah melahirkan, flu, radang selaput hidung, sakit kepala, demam dan insektisida), Vitex rotundifolia L (Obat sakit kepala, flu dan sakit mata) dan Vitex pubecen, Vahl sebagai obat sakit perut, demam, sawan, dan menambah nafsu makan (Perry, 1980).

Vitex pinnate Tour ex Linn merupakan salah satu spesies dari famili Verbenaceae. Tumbuhan ini banyak ditemukan dihutan daerah Riau dan masyarakat menyebutnya Laban atau Legung. Tanaman ini sering dipergunakan sebagai bahan obat-obatan seperti obat luka membengkak, pelancar haid, demam, penyakit kuning, busung lapar dan sakit gigi (Heyne, 1987). Setelah dilakukan pemeriksaan pendahuluan ternyata tanaman ini mengandung senyawa golongan terpenoid dan flavonoid. Beberapa senyawa flavonoid dapat bersifat antioksidan dengan tingkat aktivitas yang beragam (Torel et al 1986). Senyawa falvonoid banyak terkandung pada bagian tumbuhan seperti kulit batang, bunga dan daun.

Akhir-akhir ini penelitian antioksidan alami khususnya asal tumbuhan semakin diminati karena dinilai mempunyai tingkat keamanan yang lebih baik dibandingkan dengan antioksidan sintetik dan manfaat antioksidan yang luas dalam 
bidang makanan, kesehatan dan kosmetik. Penggunaan antioksidan sintetik sperti t-butil4-hidroksianisol (BHA) dan t-butil-4-hidroksi toluene (BHT) sebagai aditif makanan telah dibatasi disejumlah negara, kerrena senyawa ini dapat menimbulkan gangguan pada enzim-enzim hati dan paru-paru (Inatani, Nakatani dan Fuwa, 1983) Oleh karena itu penelitian pengembangan antioksidan alami perlu ditngkatkan mengingat Indonesia kaya dengan sumber daya alam hayati.

\section{METODOLOGI PENELITIAN}

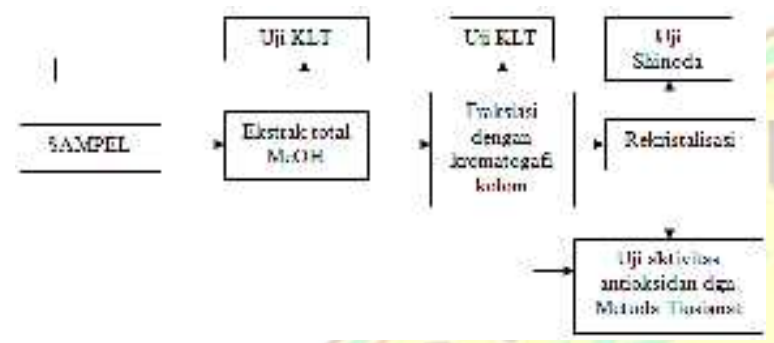

\section{HASIL DAN PEMBAHASAN}

\section{A. Isolasi senyawa flavonoid}

Hasil perkolasi serbuk kulit batang legung (Vitex pinnate Tour ex Linn) dengan metanol diperoleh ekstrak total yang berwarna coklat kehitaman sebesar $11,12 \%$, kemudian setelah diekstraksi beberapa kali dengan heksan menghasilkan ekstrak hijau kehitaman sebanyak 5,8879 g (Tabel 1). Hal ini menujukkan bahwa ekstrak metanol telah dibebaskan dari senyawa yang kepolarannya rendah seperti lemak, terpen, xantofil sebesar $0,47 \%$.

Tabel 1. Hasil perkolasi dengan metanol

\begin{tabular}{|c|c|c|l|}
\hline $\begin{array}{c}\text { 1.25 kg serbuk } \\
\text { kulit batang } \\
\text { legung }\end{array}$ & $\begin{array}{c}\text { Berat } \\
\text { ekstrak } \\
(\mathbf{g})\end{array}$ & $\begin{array}{c}\text { \% } \\
\text { Berat }\end{array}$ & Keterangan \\
\hline Ekstrak metanol & 139,044 & 11,12 & $\begin{array}{l}\text { Berwarna } \\
\text { coklat } \\
\text { kehitaman }\end{array}$ \\
\hline Ekstrak heksan & 5,8879 & 0,47 & $\begin{array}{l}\text { Berwarna } \\
\text { hijau } \\
\text { kehitaman }\end{array}$ \\
\hline
\end{tabular}

Untuk memastikan golongan senyawa yang terkandung di dalam

\section{Tabel 2. Hasil uji shinoda ekstrak metanol}

\begin{tabular}{|c|c|l|}
\hline $\begin{array}{c}\text { Ekstrak } \\
\text { metanol }\end{array}$ & Uji shinoda & Keterangan \\
\hline $4 \mathrm{mg}$ & $\begin{array}{c}\text { EtOH + pita Mg } \\
\text { + HCLp }\end{array}$ & $\begin{array}{l}\text { Larutan warna } \\
\text { merah lembayung }\end{array}$ \\
\hline
\end{tabular}

\section{Ekstrak}

Tabel 3. Hasil uji KLT terhadap ektrak metanol

\begin{tabular}{|l|l|l|}
\hline No & Eluen & Keterangan \\
\hline 1 & Etil asetat $(100 \%)$ & Noda tidak terpisah \\
\hline 2 & $\begin{array}{l}\text { Etil asetat : Metanol } \\
(9: 1)\end{array}$ & $\begin{array}{l}\text { Noda terpisah kurang } \\
\text { baik, terdapat dua noda }\end{array}$ \\
\hline 3 & $\begin{array}{l}\text { Etil asetat : Metanol } \\
(8: 2)\end{array}$ & $\begin{array}{l}\text { Noda terpisah baik, } \\
\text { terdapat empat noda }\end{array}$ \\
\hline
\end{tabular}

Tabel 4. Hasil pemisahan kromatogafi kolom

\begin{tabular}{|c|c|l|}
\hline $\begin{array}{c}\text { No } \\
\text { Fraksi }\end{array}$ & $\begin{array}{c}\text { No } \\
\text { Tabung }\end{array}$ & \multicolumn{1}{|c|}{ Keterangan } \\
\hline 1 & $1-16$ & $\begin{array}{l}\text { Fraksi berupa padatan kuning, } \\
\text { memberikan satu noda dengan } \\
\mathrm{Rf}=0,68\end{array}$ \\
\hline 2 & $17-28$ & $\begin{array}{l}\text { Fraksi berupa padatan kuning, } \\
\text { memberikan satu noda dengan } \\
\mathrm{Rf}=0,58\end{array}$ \\
\hline 3 & $29-40$ & $\begin{array}{l}\text { Fraksi berupa cairan kuning tua, } \\
\text { memberikan dua noda yang } \\
\text { memanjang dan berimpit }\end{array}$ \\
\hline 4 & $41-52$ & $\begin{array}{l}\text { Fraksi berupa cairan coklat } \\
\text { muda, memberikan noda yang } \\
\text { memanjang dan berekor }\end{array}$ \\
\hline 5 & $53-70$ & $\begin{array}{l}\text { Fraksi berupa cairan coklat tua, } \\
\text { memberikan noda yang } \\
\text { memanjang dan berekor }\end{array}$ \\
\hline
\end{tabular}

Pada pemisahan dengan kromatogafi kolom (Tabel 4) didapat 70 buah fial. Eluen yang digunakan dimulai dari etil asetat sampai metanol yang tingkat kepolarannya dinaikkan secara bergadien. Hasil fraksinasi tersebut setelah dilakukan uji kromatogafi lapis tipis memberikan harga $\mathrm{Rf}$ yang bervariasi. Tiap-tiap fial yang menujukan harga Rf yang sama digabungkan sehingga 
diperoleh lima fraksi. Dari data uji KLT hasil fraksinasi dapat diketahui bahwa ada beberapa fraksi yang pemisahannya kurang baik sehingga harga $\mathrm{Rf}$ sulit untuk ditentukan. Fraksi 1 dan fraksi 2 menghasilkan satu noda dengan Rf masingmasing 0,68 dan 0,58 .

Tabel 5. Hasil uji KLT kristal murni fraksi 2

\begin{tabular}{|c|l|c|}
\hline No & Perbandingan eluen & Nilai Rf \\
\hline 1 & Etil asetat $(100 \%)$ & $\begin{array}{c}\text { Noda tidak } \\
\text { naik }\end{array}$ \\
\hline 2 & Etil asetat : Metanol $(9: 1)$ & 0,32 \\
\hline 3 & Etil asetat : Metanol $(8: 2)$ & 0,58 \\
\hline
\end{tabular}

Tabel 6. Hasil rekristalisasi fraksi 2 dan uji shinoda

\begin{tabular}{|c|l|}
\hline Berat kristal murni (g) & \multicolumn{1}{c|}{ Uji shinoda } \\
\hline 0,1065 & $\begin{array}{l}\text { Larutan merah } \\
\text { lembayung }\end{array}$ \\
\hline
\end{tabular}

Untuk mendapatkan hasil yang sangat murni kristal yang diperoleh harus dilakukan rekristalisasi. Akan tetapi untuk fraksi satu jumlah kristalnya sangat sedikit dan setelah dilakukan uji aktivitas antioksidan, fraksi satu menujukkan aktivitas yang terkecil dibanding kelima fraksi sehingga hanya fraksi dua yang direkrisalisasi mengingat aktivitasnya yang terbesar Hasil rekristalisasi fraksi dua berupa kristal berwarna kuning dan setelah dilakukan uji KLT (Tabel 5) telah menunjukkan satu noda dengan berbagai eluen Rf dari fraksi 2 (Fr.2) dengan eluen EtOAc : $\mathrm{MeOH}(9: 1)=0,32$ dan EtOAc : $\mathrm{MeOH}(8: 2)=0,58$. Kristal murni yang diperoleh dilakukan uji shinoda terbentuk larutan berwarna merah lembayung, ini menunjukkan bahwa kristal ini merupakan senyawa golongan flavonoid.

\section{B. Uji aktivitas Antioksidan} linoleat-tiosianat ini adalah asam linoleat yang merupakan asam lemak tidak jenuh. Radikal merupakan senyawa oksidator. Proses oksidasi lemak menghasilkan produk pirmer peroksida (Munim, et al, 2003). Radikal ini akan mengoksidasi ion $\mathrm{Fe}^{+2}$ menjadi $\mathrm{Fe}^{+3}$. Selanjutnya $\mathrm{Fe}^{+3}$ dengan ion CNS membentuk komplek yang berwarna merah yang dapat diukur intensitasnya pada panjang gelombang $500 \mathrm{~nm}$. Reaksi yang terjadi adalah sebagai berikut:

Ekstrak metanol kulit batang legung mempunyai daya antioksidan yang ditandai dengan menurunya absorbansi ekstrak metanol kulit batang legung dibanding dengan kontrol, dengan urutan sebagai berikut $\alpha$-tokoferol $>$ Fr. $2>$ Fr. $4>$ Fr ..3 > Fr.. $5>$ Fr. 1

Pengujian aktivitas antioksidan dari kelima fraksi dengan menggunakan metoda tiosianat, serapannya diukur pada panjang gelombang optimum $\left(\lambda_{\text {opt }}\right) 480 \mathrm{~nm}$ (Gambar 1).

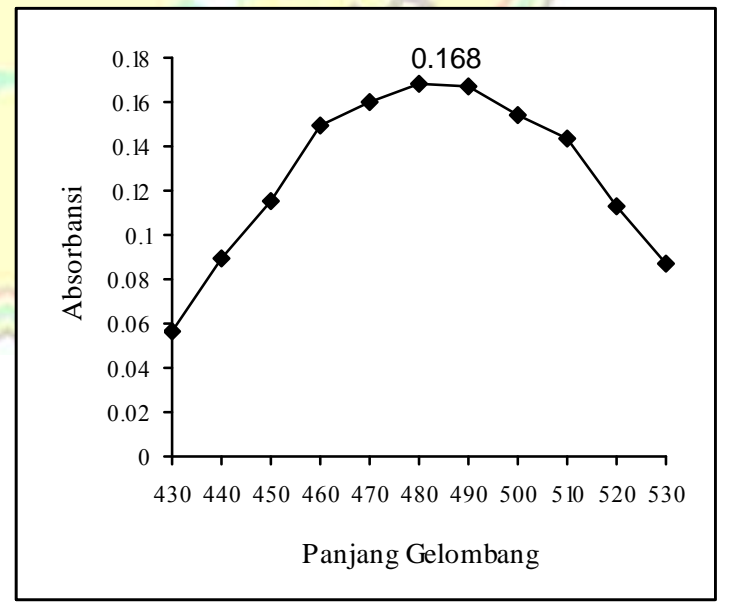

Gambar 1. Hasil penentuan $\lambda_{\text {opt }}$ larutan $\alpha$ - tokoferol

Hasil pengukuran daya antioksidan senyawa flavonoid dari lima fraksi hasil isolasi dengan menggunakan metode sistem lineleattiosianat selama 5 hari yang ditandai dengan 
menurunya absorbansi kontrol serta menggunakan vitamin E sebagai pembanding (Lihat Gambar 2). Pengaruh penambahan $\alpha$ tokoferol, dan kelima fraksi dalam proses oksidasi asam linoleat yang disimpan di dalam tabung reaksi yang tertutup pada suhu $40^{\circ} \mathrm{C}$. Dari gafik tersebut terlihat bahwa semua senyawa menghambat proses oksidasi asam linoleat dimana aktivitas kelima

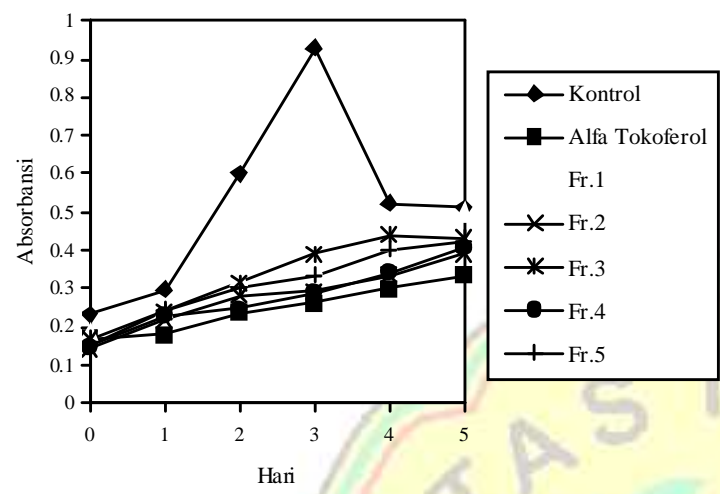

Gambar 2. Uji Aktivitas Antioksidan Ke-5 Fraksi

Fraksi ekstrak metanol lebih rendah jika dibandingkan dengan $\alpha$-tokoferol. Berikut urutan aktivitas antioksidan masingmasing fraksi:

$\alpha$-tokoferol $>$ Fr. $2 \geq$ Fr. $4>$ Fr. $3 \geq$ Fr. $5>$ Fr. 1

Berdasarkan nilai absorbansi fraksi dua (Fr.2) memiliki aktivitas yang terkuat diantara sampel uji sedangkan aktivitas fraksi empat (Fr.4) sebanding dengan Fr.2 begitu juga dengan fraksi tiga (Fr.3) dan fraksi lima (Fr.5) aktivitas kedua fraksi hampir sama. Kecuali Fr 1 menunjukan aktivitas yang terlemah.

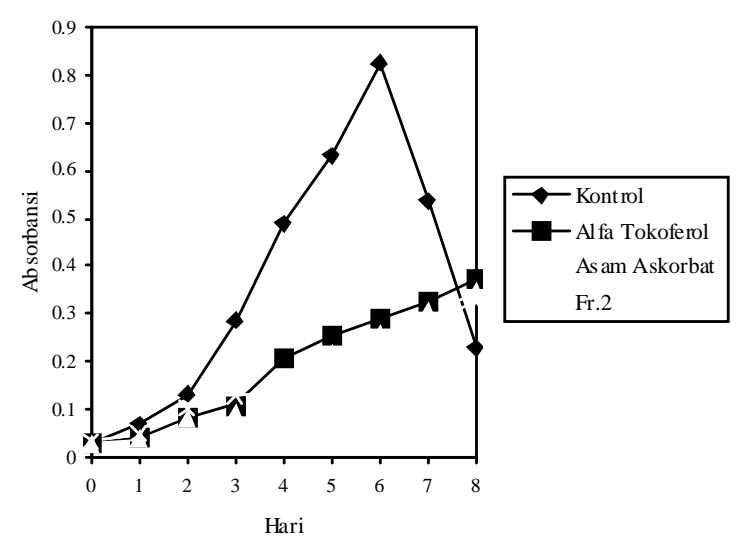

\section{Gambar 3. Uji aktivitas Antioksidan Fraksi 2 setelah direkristalisasi}

Setelah fraksi 2 dilakukan rekristalisasi dan dilakukan kembali uji aktivitas antioksidan dengan pembanding $\alpha$-tokoferol dan asam askorbat terlihat bahwa selama 8 hari aktivitas senyawa murni Fr.2 lebih stabil sebagai antioksidan (Gambar 3). Ini dapat disimpulkan bahwa Aktivitas senyawa flavonoid pada Fr.2 lebih baik dibandingkan $\alpha$-tokoferol dan asam askorbat.

Fr $2>$ asam askorbat $>\alpha$-tokoferol

Aktivitas antioksidan senyawa murni Fr.2 dapat dikatakan lagi lebih baik dari Fr.2 sebelum dimurnikan, dilihat dari aktivitas dalam menghambat proses oksidasi asam linoleat bila dibandingkan terhadap $\alpha$ tokoferol. Hal ini tentunya disebabkan oleh adanya zat pengotor yang melekat pada kristal Fr.2 sebelum dimurnikan sehingga akan mempengaruhi aktivitasnya.

\section{KESIMPULAN}

Berdasarkan hasil penelitian yang telah dilakukan dapat diambil kesimpulan bahwa:

1.Aktivitas antioksidan senyawa flavonoid dari ke lima fraksi hasil isolasi senyawa flavonoid ekstrak metanol kulit batang legung berturut-turut sebagai berikut: $\alpha$ tokoferol $>$ Fr. $2>$ Fr. $4>\operatorname{Fr} . .3>$ Fr.. $5>$ Fr.1. 
2.Fraksi dua (Fr.2) ekstrak metanol hasil rekristalisasi mempunyai aktivitas antioksidan lebih besar dari $\alpha$-tokoferol dan asam askorbat.

\section{SARAN}

Perlu dilakukan pengujian aktivitas lain dari kulit batang, daun, bunga dari tanaman Legung (Vitex pinnate Tour ex Linn).

\section{DAFTAR PUSTAKA}

Alphajit, S., 1995. Isolation and structure of limonidilactone-a Labdane diterpen from Vitex limonifolia, Australia J.Chem,48:133-137

Badami, S., Prakash, O., Donge, SH., Suresh, B., 2005, In vitro antioxidant properties of Solanum pseudocapsicum leaf ekstraks, Indian J Pharmacol., 37:251-252

Da Silva, 1B., Da Silve, ULL, mahenran, M and Jennings, RC,1980, 4'-hidroksi3,5,6,7,3',5'-heks-metoksi flavon, Phytochemistry, 19,2794.

Esteban, A., Zapata, L., Casano,M., Martin and Sabater., 2000, Peroxidase activity in Aloe vera barbadebsis commercial Gel:
Probable role in skin protection, Planta Medica, 66: 724-727

Godjevac, D., Vajs, V., Menkov, N., Telev, V., Kov, P., Milosvljev, S., 2004, Flavonoid from flowers of Chepalaria ppastricenis and Their antiradical activity, J. Serb.Chem, Soc.69:883-886.

Inatani, Nakatani dan Fuwa, 1983. Antioxidative effect of some Ginger constituen of (Rosmarinus oficinalis L) and Their Derivatives,. Agic .J.Biol. Chem.(3), 2081-2085

Perry, LM and Metzger, J.,1980, Medicine plants of east and southest Asia: The Attributed properties and sees. The MIT Press. Cambridge, Massachusetts.

Pokorni,J., Yanishlieva,N and Gordon, M.,2001, Antioxidant isolated from leaf Wax of Eucalyptus leaves, J.Agic.Biol.Chem,45,735-739.

Torel, J., dan Cilard., 1986. Antioxidant activity of flavonoid and reactivity with peroxy radical. Phytochemistry.Pergamon Press,2(25),283-38 